CADERNOS DE RELAÇÕES INTERNACIONAIS, v. 5, n.1, 2012

\title{
Narrativas de espacialidade no discurso do presidente Chávez: formação de identidades e políticas \\ Mariana Abi-Saab ${ }^{1}$
}

\begin{abstract}
Resumo
O presente trabalho procura identificar a relação do discurso do Presidente Hugo Rafael Chávez Frías com a construção da identidade e das políticas chavistas, por meio do trabalho de Lene Hansen e das contribuições teóricas de Rob Walker. A partir desse intuito, foram selecionados aqueles discursos que apresentavam narrativas sobre a espacialidade, procurando identificar nelas representações de diferenciação/negação e vinculação/afirmação envolvidas no processo de formação da identidade e das políticas chavistas. Buscou-se, ademais, mostrar o vínculo de tais representações com o cenário doméstico e internacional. Finalmente, foram reconhecidas ao longo do trabalho, a partir de tais representações e discursos, as práticas de inclusão e exclusão dentro da sociedade venezuelana, assim como na inserção do país no cenário internacional.
\end{abstract}

\section{Palavras-Chave}

Discurso, identidade, políticas, Hugo Chávez, espacialidade.

\section{Abstract}

The present study seeks to identify the relation of President Hugo Rafael Chávez Frías discourse with the construction of the Chavista identity and policies. This will be possible having as theoretical support the work of Lene Hansen and the contributions of Rob Walker. In order to do so, those discourses that presented spatiality narratives were selected so to identify representations of differentiation/denial and linking/affirmation involved in the process of formation of Chavista identity and policies. Furthermore, this work attempts to present the linkage of such representations with the domestic and the international scenario. At the same time, from these representations and discourses, practices of inclusion and exclusion within the Venezuelan society and regarding its insertion into the international scenario, were recognized.

\section{Keywords}

Discourse, identity, politics, Hugo Chávez, spatiality

\footnotetext{
${ }^{1}$ Formada em Relações Internacionais pela PUC-Rio. O artigo forma parte da monografia de graduação ganhadora do prêmio Gerson Moura 2011. Mariana Abi-Saab é também autora do artigo "Entre a Integração Política e a Politização: A Adesão da Venezuela ao MERCOSUL”, publicado na Cadernos de Relações Internacionais.
} 
"Yo he decidido hablar de cosas imposibles, porque de lo posible se sabe demasiado" Resumen de noticias, Silvio Rodríguez. "Could language injure us if we were not, in some sense, linguistic beings who require language in order to be?" Excitable Speech, Judith Butler.

\section{Introdução}

\section{I) Da apresentação do tema e do problema de pesquisa}

Em fevereiro de 1999, o Presidente da Venezuela, Hugo Rafael Chávez Frías, começa o seu mandato presidencial sob o juramento de convocar um referendo para escolher a Assembleia Nacional Constituinte encarregada de redigir a nova Constituição do país. Após a aprovação, em dezembro desse mesmo ano, da nova Carta Magna, o Presidente é reeleito e inicia, em julho de 2000, um novo período presidencial de mais seis anos de governo. Nesse mandato, graves instabilidades políticas caracterizaram o cenário venezuelano: no dia 11 de abril de 2002, manifestações da oposição ao governo pediram a renúncia do Presidente. Um governo transitório de dois dias tomou o poder, e em seguida teve-se a volta de Hugo Chávez assumindo novamente a presidência do país no dia 14 de abril ${ }^{2}$ (MORENO, 2008, p.131-134).

Em agosto de 2004, um Referendo Revogatório - que visava votar a favor ou contra a revogação do mandato do Presidente Chávez - é feito no país sob intensa tensão política. Como resultado, o Presidente obteve apoio para terminar seu mandato, debilitando profundamente a oposição venezuelana. Chávez candidata-se para a reeleição e, em dezembro de 2006, é escolhido com o apoio de 63\% da população para governar durante o período de 2007-2013. Em janeiro de 2007, no discurso inaugural do novo mandato, o

\footnotetext{
${ }^{2}$ Ditos acontecimentos começaram no dia 11 de abril de 2002 com duas manifestações (uma em apoio e outra em protesto ao governo) que terminaram em acontecimentos violentos no centro da cidade, deixarando 19 mortos e mais de 200 feridos enquanto o Presidente falava em cadena nacional. Esses acontecimentos resultaram na exigência da saída do poder do Presidente no dia 12, o que é interpretado por alguns setores como um Golpe de Estado. No entanto, Chávez voltou ao poder no dia 14. Tais eventos serão chamados ao longo do trabalho de "os acontecimentos de abril de 2002". Com relação à sua postura sobre ditos acontecimentos, a Organização de Estados Americanos publicou alguns comunicados como "Situação na Venezuela”, (ORGANIZAÇÃO DE ESTADOS AMERICANOS 2002a) e "Apóio à democracia na Venezuela” (ORGANIZAÇÃO DE ESTADOS AMERICANOS 2002b). Essas publicações denominaram os acontecimentos de "alteração da ordem constitucional", "fatos lamentáveis de violência" e rejeitaram “categoricamente qualquer tentativa de Golpe de Estado”.
} 
Presidente apresentou um conjunto de leis “revolucionárias” que implicariam uma reforma profunda da Constituição Bolivariana, visando conseguir o estabelecimento definitivo da República Socialista Bolivariana da Venezuela. Essas políticas foram rejeitadas no dia 2 de dezembro de 2007 na votação da Reforma Constitucional, quando a maioria venezuelana negou-se a aceitar a proposta do Presidente e a oposição ao governo conseguiu a sua primeira vitória no campo eleitoral.

É importante mencionar, no entanto, que após a Emenda Constitucional realizada em fevereiro de 2009 - a qual possibilita a reeleição indefinida do mandatário de Estado - o Presidente Hugo Chávez é, desde 2010, o candidato oficial pelo PSUV (Partido Socialista Unido de Venezuela) para as eleições que terão lugar em outubro de 2012, podendo ficar no poder por mais seis anos (PSUV, 2007).

Atualmente as pessoas que apoiam o Presidente e seu governo identificam-se como chavistas, enquanto que aqueles que se posicionam contra o seu governo denominam-se de oposição. Em onze anos de governo (1999-2010) o Presidente Chávez tem desenvolvido uma assídua comunicação com a população. Linguistas e comunicadores venezuelanos manifestam a dificuldade de organizar um estudo dos discursos do Presidente devido não só à sua quantidade, mas também à longa duração de cada discurso. Mesmo assim, apontam que, no final de 2006, o Presidente teria falado em cadena nacional (transmissão conjunta na rádio e na televisão e sem possibilidade de ver outra mensagem no espectro radioelétrico venezuelano) uma média de 40 minutos diários desde o início do governo (PASQUALI, 2006). Somam-se ainda a essas “cadenas” a transmissão de mensagens através do seu programa dominical Aló, Presidente o qual durou uma média de cinco horas por programa entre 2000 e 2007, aumentando para sete horas entre julho e setembro de 2007 (KRAUZE, 2008, p.90). Na visão do historiador Enrique Krauze: “Chávez tem inaugurado um estilo inédito nos anais políticos: ele governa ‘ao vivo’, frente às câmeras”. Essa forma pessoal de se expressar discursivamente afasta-o das formas verbais tradicionalmente empregadas pelos governos anteriores da história da Venezuela, as quais tinham mantido uma distância com “el pueblo" (ROMERO, 2005,p.372). 
O programa Aló Presidente, é um exemplo desta prática inédita. Iniciado em maio de 1999, o programa pretendia, em um primeiro momento, unicamente receber chamadas de cidadãos, que deveriam apresentar suas necessidades ${ }^{3}$. O Presidente escutaria o caso e o administraria, destinando alguém para que cuidasse do assunto. No Aló Presidente de número 1, o apresentador começou o programa com as seguintes palavras:

\begin{abstract}
Comenzamos hoy domingo 23 de mayo de 1999 un programa especial, sin precedentes en la historia de la radiodifusión venezolana. Por primera vez en Venezuela, un Presidente de la República conduce su propio programa de opinión y participación popular, con el único interés de escuchar el clamor del pueblo. A partir de este momento y por espacio de una hora, se establecerá el gran diálogo entre el Jefe de Estado y ustedes que nos escuchan ahora en toda la República. (ALÓ PRESIDENTE, 1999)
\end{abstract}

O Programa passou, no entanto, a não ter limite de tempo de transmissão, conferindo ao Presidente a possibilidade de aparecer na televisão durante o tempo que desejasse. Pode dizer-se que existem elementos que levam a uma onipresença do Presidente Chávez na mídia (KRAUZE, 2008, p.89-90).

Atualmente, na Venezuela, existe um único canal de televisão plenamente independente: Globovisión. Até 2006, RCTV era o canal de maior audiência no país (28,1\%) (KRAUZE, 2008, p. 89). Com o anúncio de não renovação do contrato desse canal, a televisão oficialista (simpatizante de Chávez) domina a mídia. Desde 2002, com a cobertura dos acontecimentos de abril desse ano e o respaldo da greve petroleira em inícios de dezembro de 2001, o governo começou a buscar, mediante um leque de medidas legais coercitivas, o controle dos meios midiáticos de massa, no intuito de atrair os outros canais privados para uma linguagem “dentro da linha” (oficialista). Como exemplo disto, em novembro de 2006, quinze dias antes das eleições presidenciais, Venevisión dedicou 84\% da sua informação política à posição oficialista enquanto Televen dedicou 68\% (KRAUZE, 2008, p.90).

Com relação ao contexto político venezuelano, este se apresenta bastante polarizado. Sociólogos e analistas políticos apontam "violência verbal” e “exclusão e discriminação

\footnotetext{
${ }^{3}$ Vale ressaltar que, em princípio, a proposta do Aló Presidente era de ser um programa apresentado aos domingos das $9 \mathrm{~h}$ às $10 \mathrm{~h}$ da manhã.
} 
política” (BLANK \& CALCAÑO, 2009) como características do governo Chávez. Essa polaridade política, que diferencia a oposição do oficialismo, se reflete nas representações internas e internacionais do Presidente. Domesticamente, o governo apresenta um discurso político agressivo frente à representação do "Outro” - a oposição ao governo -, chamado de “vendepatria”, "burguês”, “oligarca”, “golpista” “pitiyanqui”, como será visto ao longo do presente estudo. Esse “Outro” é identificado como “inimigo da Revolução Bolivariana”, “traidor da Pátria e do povo” (COLMENARES, 2008). Já internacionalmente, o discurso agressivo é direcionado contra países identificados como aliados do imperialismo americano. No período em que os EUA eram presididos por George W. Bush, o país foi catalogado por Chávez como o “demônio”, o "país do capitalismo selvagem”, o “império opressor dos povos”. O mesmo critério de inimizade foi aplicado à descrição do governo de Álvaro Uribe da Colômbia: “uma ameaça para a Venezuela” por ser um "triste peão do império” (COLMENARES, 2008).

Em face ao exposto sobre a conjuntura venezuelana, surge o seguinte questionamento: Como se apresenta a construção da identidade e das políticas chavistas? Qual a relação destas com o discurso do Presidente Chávez?

A hipótese aqui defendida é que o discurso do Presidente Chávez apresenta representações dicotômicas e binárias sobre aqueles que apoiam e aqueles que diferem do seu governo, estabelecendo uma dinâmica de inclusão de alguns em detrimento da exclusão de outros e definindo o processo de formação da identidade chavista e das políticas adotadas pelo governo. Tais representações se nutrem e, ao mesmo tempo, têm implicações no cenário doméstico e internacional, e se apresentam por meio de narrativas espaciais específicas. Desta forma, procura-se identificar a relação do discurso do presidente Hugo Rafael Chávez Frías com a construção da identidade e das políticas chavistas, reconhecendo nesse processo práticas de inclusão e exclusão. A partir desse intuito, foram selecionados aqueles discursos do Presidente Chávez que apresentam narrativas sobre a espacialidade identificando neles as representações de diferenciação/negação e vinculação/afirmação envolvidas no processo de formação da identidade e das políticas chavistas. Finalmente, a partir de tais representações, realiza-se uma procura por práticas de 
inclusão e exclusão dentro da sociedade venezuelana, bem como da inserção/exclusão do país no cenário internacional.

\section{Do embasamento teórico}

O trabalho de Lene Hansen, Security as Practice, pesquisa a não neutralidade do discurso para entender um caso de política externa. A pertinência desse trabalho para o estudo do contexto venezuelano apresenta-se uma vez que Hansen valoriza a linguagem para entender a formação de políticas e identidades. Para os autores pós-estruturalistas como Hansen, “a linguagem não é neutra, ela é social e política” e, por isso, instável. Nas suas palavras:

To understand language as political is to see it as a site for the production and reproduction of particular subjectivities and identities while others are simultaneously excluded (HANSEN, 2006, p.17).

To theorize $[. .$.$] policy as discourse is to argue that identity and policy are$ constituted through a process of narrative adjustment that they stand, in social science terminology, in a constitutive, rather than causal, relationship (HANSEN, 2006, preface xvi).

Na mesma medida em que a identidade constitui as políticas, as políticas também constituem as identidades. Assim, ambas são "tanto sujeitos quanto objetos continuamente restabelecidas, negociadas e reformadas”. A linguagem é caracterizada como instável já que ela depende do contexto (do grupo social, lugar e propósito em que é utilizada), questionando com isto qualquer noção de inevitabilidade, naturalização ou normalização da mesma. Uma grande contribuição teórica da autora, com relação à ontologia da formação das identidades, é a sua exposição sobre a existência não só de um processo de diferenciação, mas também de um processo de vinculação - linking. Hansen consegue, dessa forma, aprofundar-se mais na complexidade do procedimento de formação da identidade, sendo o processo de vinculação/afirmação tão necessário quanto o de diferenciação/negação.

Hansen apresenta uns diagramas que explicam de forma clara este processo de formação de identidades (vide figura 1). Este diagrama ilustra o processo específico de 
formação da identidade das mulheres do século XIX, às quais se outorgavam discursivamente uma série de características (emocional, maternal, simples, dependente) sempre justapostas à identidade do homem (racional, intelectual, complexo, independente). É nesse sentido que se afirma a necessidade de um Outro para a existência do Eu, sendo este o elemento “relacional” da definição de identidade de Hansen (vide figura 2).

Figura 1 - Processo de vinculação: identidade positiva
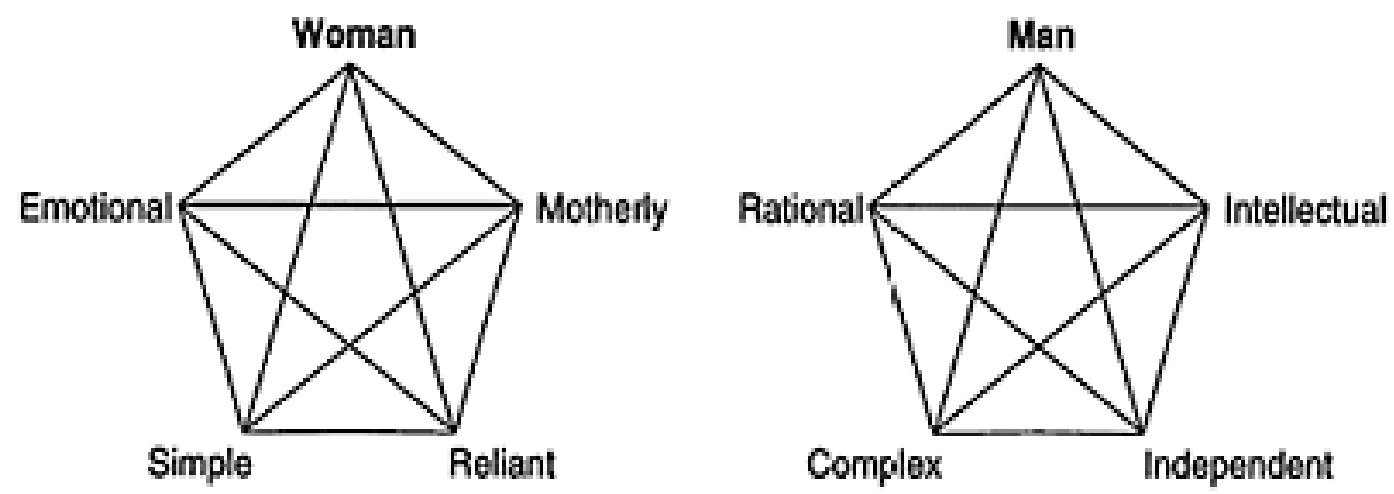

Figura 2 - Vinculação e Diferenciação

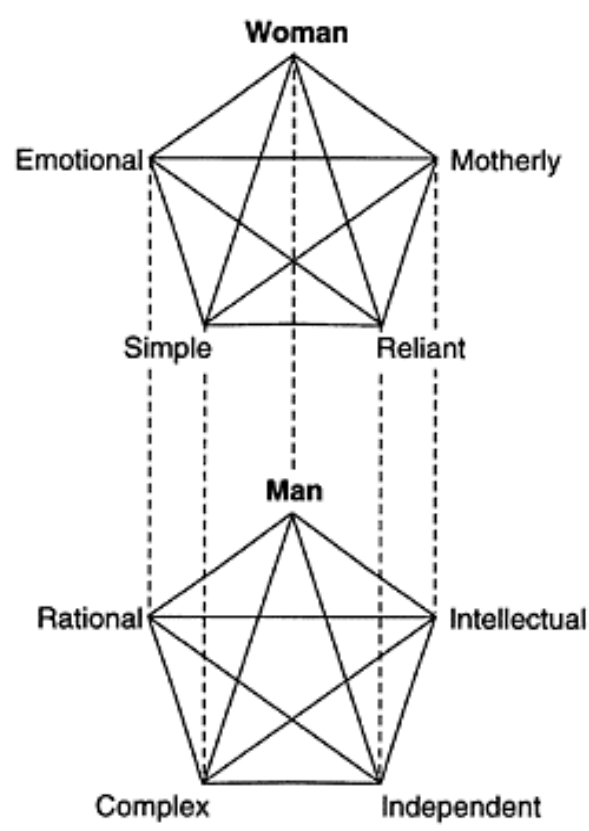


Ao analisar a conjuntura venezuelana, ambos os processo - de vinculação e de negação - podem ser reconhecidos. O discurso do presidente Chávez expõe um apelo de união entre as nações que em outros contextos foram oprimidas, em especial as nações latino-americanas, os pobres, os militares, os obreiros e os indígenas têm sido incluídos no discurso visando dar-lhes a voz que antes não tinham e identificando-os sob a linguagem comum de antigos excluídos. Essa afirmação realiza-se em detrimento de um Outro que é representado como a "oligarquia”, a "Quarta República”, os "ricos”, a “oposição”, os “meios vendidos”, os “neoliberais”, a "burguesia apátrida”, os "pitiyanquis traidores”, os “filhos do imperialismo". Tais representações formam parte do cotidiano dos adjetivos destinados à oposição venezuelana, justapondo-se às representações da identidade chavista (COLMENARES, 2008).

É importante mencionar que Hansen também ressalta o fato de que nem sempre a diferenciação é sinônimo de uma radical negação do Outro. Os diferentes graus de alteridade (Otherness) em que se representa o Outro - em níveis mais ou menos polarizados e com representações mais ou menos reconciliáveis - serão levados em consideração para estudar de que forma a “diferença” é representada nos discurso do Presidente Chávez.

Destarte, as obras de Rob Walker Inside/Outside: International Relations as Political Theory e The Double Outside of the Modern International ilustram como na modernidade formam-se as noções de inclusão e exclusão consolidadas no princípio de soberania da política moderna, o qual constitui um dentro e um fora global. O espaço-temporalidade do Estado-Nação: as suas fronteiras, o perigo do tempo e da contingência, a noção de uma identidade não problemática ao interior do Estado, entre outras, são premissas da política moderna. Para Walker, o questionável deste mundo moderno é sua criação de uma visão hegemônica baseada em lógicas de diferenciação entre o doméstico e o internacional, o soberano e o anárquico, o Eu e o Outro, que trouxeram consigo práticas de inclusão e exclusão não problematizadas:

\footnotetext{
${ }^{4}$ Embora o período da Quarta República seja entre 1830 e 1999, Chávez o usa para referir-se de maneira pejorativa à chamada era da Democracia representativa, surgida a partir do Pacto de Punto Fijo (1958) até a mudança da Constituição em 1999. No entanto, em alguns discursos Chávez faz referência ao fato da Quarta República ter surgido como fruto da traição a Bolívar, uma vez que é em 1830 que a Grande Colômbia (projeto de Bolívar) se dissolve.
} 
The story of modern politics is a story of a pattern of inclusion and exclusion within a modern system of states, within the international (WALKER, 2006, p.66).

I offer a reading of modern theories of international relations as a discourse that systematically reifies an historically specific spatial ontology, a sharp delineation of here and there, a discourse that both expresses and constantly affirms the presence and absence of political life inside and outside the modern state and the only ground on which structural necessities can be understood and new realms of freedom and history can be revealed (WALKER, 1993, preface ix).

É interessante ver que esse discurso de representações divisórias entre aqui/lá, dentro/fora, identidade/diferença, presente na dinâmica do Estado-Nação e na sua projeção moderna frente ao internacional, é também sistematicamente reedificado nos discursos do Presidente Chávez, a partir das representações de nós/eles, governo/oposição, povo/oligarquia, governo atual/governos anteriores, revolucionários/contrarrevolucionários, patriotas/traidores, pobres/ricos, países oprimidos/países imperialistas, socialismo/capitalismo, entre outras. Dessas representações, pode-se associar o que Walker aponta como uma construção da identidade política, é dizer, uma prática de legitimação de várias formas de inclusão e exclusão.

A leitura da obra de Walker é, assim, enriquecedora porque, por meio dela, podemos entender que no contexto venezuelano, também existe a construção de uma narrativa espacial que inclui alguns e exclui outros em termos de alianças, existências e presenças. Esse tipo de exclusões por parte do Estado é altamente preocupante para Walker já que muitas vezes não são problematizadas como resultado da naturalização da existência e da autoridade do Estado. Este, por sua vez, consegue legitimidade por meio da representação de anarquia fora do Estado (no campo internacional) e de ordem dentro dele (no campo doméstico e soberano), reedificando primeiro a ameaça constante vinda de fora e segundo a necessidade iminente de manter o Estado forte e soberano para decidir sobre a vida (e a morte) de sua população. Daí a importância de, ao longo do trabalho, chamar a atenção às narrativas de ameaça e às práticas de exclusão. 


\section{I) O discurso do Presidente Chávez: relevância e linguagem de guerra}

Em onze anos de presidência de Hugo Chávez (1999-2010), o governo tem sido caracterizado como mediático (KRAUZE, 2008, p.90), devido à importante presença do Presidente na mídia e ao vínculo pessoal estabelecido com quem escuta o discurso. O interessante é observar que a lógica presente nos seus discursos não é só a de governar midiaticamente, o que já é uma inovação, mas de atuar em diversas capacidades: como historiador oficial, fiscal da história, representante do Poder Executivo e Legislativo, apontando mesmo, em sua agenda, as decisões do país. Isso caracteriza a individualização e personificação do governo em Hugo Chávez. É também relevante perceber como, nos discursos do Aló Presidente ou cadena nacional, Chávez procura ter no espaço objetos de significado nacional para a Revolução e faz explícita referência a estes. O Presidente normalmente se apresenta nos Aló Presidentes em lugares históricos ou em lugares onde se esteja desenvolvendo algum dos projetos do governo. Além disso, os espaços apresentam símbolos pátrios, quadros com personagens históricas, com a predominância da cor vermelha (a da Revolução).

Exemplo dessa contextualização espacial é o trecho do início do programa especial do Aló Presidente em comemoração aos 200 anos do dia 19 de abril de 1810, realizado no dia 18 de abril de 2010:

En cadena nacional de radio y televisión desde aquí, desde la Casa Amarilla, histórico escenario, testigo de cuántos acontecimientos. Bueno, y aquí en este espacio, aquí frente a este histórico balcón, ahí la plaza mayor de Caracas, la plaza Bolívar, la Caracas histórica, aquí está la Caracas de 500 años, el corazón de esta Caracas. Caracas la cuna de la Revolución latinoamericana y caribeña. ¡Una de las cunas pues!, una de las más grandes cunas de la Revolución. (CHÁVEZ, 2010).

Com relação ao tom dos discursos, é necessário ressaltar a linguagem de guerra do Presidente, uma vez que traz consigo um tom muito mais agressivo. Deve lembrar-se que Chávez é licenciado em Ciências e Artes Militares, o que explica, em certa medida, a familiaridade do Presidente com esse tipo de linguagem. Eduardo Krauze relata uma intervenção do Presidente no Programa La Hojilla, um programa de opinião de tendência oficialista, no qual, uns dias após a rejeição do referendo de 2 de dezembro de 2007, 
Chávez participou por meio de uma chamada telefônica. Após ver a intervenção de Chávez, Krauze comenta:

Me llama la atención la insistencia en el uso de términos guerreros: adversarios, enemigos, armas, tiros. Quienes votaron por el No [contra a reforma Constitucional] son 'lacayos', 'pitiyanquis', 'brazos del imperio', 'conspiradores' [...] Para Chávez 'ésta es una batalla mundial', [...] 'hablo al mundo, nosotros nos estamos enfrentando con el imperio' [...]. (KRAUZE, 2008, p.53).

Marco Aponte Moreno defende, em sua tese de doutorado em Filosofia intitulada Metaphors in Hugo Chávez's political discourse, a ideia de que, no discurso de Chávez, a linguagem de guerra está presente normalmente na hora de defender a Revolución Bolivariana e no momento de qualificar os seus oponentes, os governos anteriores ou o imperialismo americano. No caso da Revolución Bolivariana, Aponte Moreno argumenta que ao usar metáforas de conflito para conceituar o projeto político, Chávez atribui à sua revolução o elemento violento que lhe falta na prática, e dessa forma a legitimaria como uma revolução genuína (MORENO, 2008, p.129).

Contudo, as referências à oposição ilustram o momento em que Chávez sobe ainda mais o tom de guerra e entra em uma desqualificação do "oponente”. Nos discursos estudados por Aponte Moreno entre 2002 e 2004, o autor mostra que, ao se tratar da oposição, o Presidente faz uso de metáforas relacionadas a fontes do crime ou de conflitos. Chávez trata a oposição como rebelde e terrorista ao afirmar que "estos grupos desesperados para montarse en esta conspiración abierta”; "grupos de saboteadores con actitudes de terroristas”. Igualmente, a oposição é tratada por Chávez como ladra, traiçoeira e usurpadora: "Estos golpistas que quisieron quitarle al pueblo la comida para que entonces el pueblo saliera a las calles a saquear y para que se generara una violencia y muertos”. São encontradas referências verbais explícitas que classificam a oposição como assassina: “Cuando empezó la crisis aquí nos quisieron ahorcar y ahogar” (MORENO, 2008, p.155156). A desqualificação à oposição se acentua ainda mais quando ela é (arbitrariamente, em muitos casos) associada ao imperialismo norte-americano e, portanto, vista como traidora 
da nação (MORENO, 2008, p.156). No Aló Presidente do dia 20 de julho de 2008, alguns meses antes das eleições para governadores e prefeitos da Venezuela, Chávez disse:

Imagínate si la alcaldía mayor de Caracas vuelve a caer en manos de la oposición vendepatria, porque toda esa oposición es vendepatria [...] como la tuvieron y la usaron para matar gente, para dar un golpe de Estado [...] no se trata de la oposición nada más, no, eso es mucho más que la oposición. Son los vendepatrias, son los contrarrevolucionarios, son pitiyanquis $^{5}$ que son peores que los yanquis. Ellos quisieron que los yanquis volvieran a gobernar este país, porque lo gobernaron, se llevaron todo el petróleo, se llevaron las riquezas nuestras [...] Imagínense que el estado Vargas vuelva a caer en manos de la oposición y el estado Aragua y Carabobo. Si eso ocurriera, el año que viene no habría paz aquí. Sería un año de guerra, porque ellos si vienen es por mí. Eso es lo que ellos quieren sacarme de aquí [...] ellos son peones de un juego de ajedrez ¿Quién mueve los peones? El imperialismo y la oligarquía, sin falla. [...] Apuntemos bien las armas hacia el enemigo, el enemigo internacional, el enemigo interno (KRAUZE, 2008, p.93).

É necessário perceber como o discurso do Presidente Chávez está continuamente sugerindo uma ameaça, seja interna ou externa, de guerra ou de golpe de Estado por parte da oposição ou de invasão a partir das reiteradas denúncias de planos americanos, em aliança com a oposição, de invadir o território venezuelano na procura por recursos naturais ou para tirar (assassinar) o Presidente. Na realidade, estas mensagens de ameaça começaram quando o governo venezuelano supostamente descobriu, em 2004, 240 paramilitares colombianos que estavam em solo venezuelano e planejavam matar o Presidente. No entendimento de Chávez, a ameaça surge dessas supostas provas que ele tem, mas também da própria crítica ou divergência contra o seu governo, seguindo a visão reducionista de "se não estão comigo, estão contra mim”. No discurso do dia 16 de maio de 2004, analisado por Marco Aponte Moreno, Chávez disse: “[H]oy sencillamente la oligarquía venezolana, la oligarquía colombiana, lacayas las dos del imperialismo norteamericano sembraron los paramilitares aquí en Caracas para tratar de matar al Presidente de Venezuela” (MORENO, 2008, p.158).

Com esta linguagem presente no discurso chavista, existem só dois tipos de venezuelanos: eles (a oposição) apresentados sempre negativamente como os responsáveis

\footnotetext{
${ }^{5}$ Chávez usa o termo pitiyanqui para se referir aos que apoiam os americanos (yanquis).
} 
pelos erros políticos e a ameaça à nação; e nós (os que apoiam Chávez), sempre com uma auto representação positiva como agentes das mudanças e do melhoramento sócio-político do país. Contudo, esses dois grupos passam a ser irreconciliáveis e mutuamente inassimiláveis na medida em que discursivamente eles representam uma ameaça para a nossa existência. A partir dessa narrativa reducionista -de uma revolução que se traduz em guerra, de oponentes desqualificados moral e politicamente e da iminência de conflito surge, na narrativa chavista, um cenário que ilustra constantemente a ideia de campo de batalha, em que é necessário definir quem são os amigos e os inimigos. Esse cenário estabelece uma nova espacialidade, fora da Venezuela e ao interior dela, baseada na premissa mutuamente excludente: “o amigo do meu inimigo é meu inimigo” e vice-versa.

\section{II) Novo mapa de amigos e inimigos que define políticas de aliança e rivalidade}

A reedificação de uma determinada ontologia espacial baseada na representação do cenário internacional como um campo de batalha dividido entre amigos e inimigos, provoca a necessidade de desenvolver uma política externa com capacidade de resposta frente a tal cenário. Seguindo a ideia tradicional de batalha, onde se define claramente o território dos que se enfrentam, procura-se a não contaminação entre esses campos e se estabelece uma espacialidade mutuamente excludente onde não é concebível a convivência com o campo do inimigo/Outro.

Mesmo que se possa entender que se trata unicamente a noção do espaço no sentido metafórico, é importante observar que se considera como espaço o local no qual é possível existir a presença, mais ou menos afastada, de um ou mais corpos. Isto se aplica tanto no âmbito doméstico quanto no internacional. Assim, quando é abordada a negação do espaço, não se faz referência a um sentido metafórico, mas a uma compreensão bastante tangível, uma vez que se trata da negação da possibilidade de estar presente ou de participar de um determinado espaço, seja este uma instituição ou uma empresa, do campo político ou econômico.

Retomando o tema da política externa venezuelana, o professor e internacionalista venezuelano Carlos Romero, quem tem dedicado vários dos seus trabalhos acadêmicos ao 
estudo da evolução da política externa do país, reconhece que, a partir de 1958, esta apresentou uma clara vocação andina e caribenha, onde a primeira era o seu maior compromisso regional através da Comunidade Andina de Nações (CAN). Na atualidade, o Presidente Chávez vem se afastando de forma determinante dessa vocação desde que a Venezuela denunciou drasticamente o Acordo de Cartagena, saindo da CAN em julho de 2006, bem como ao desenvolver novos espaços de interação e aliança com os países de outras regiões (ROMERO, 2007). A política externa venezuelana do Presidente Chávez enfatiza também aliados não tradicionais como Irã, Síria, Bielorrússia, Rússia, China, Vietnã, Malásia, países da África e da Organização de Países Exportadores de Petróleo (OPEP); ao mesmo tempo em que procura a criação de um Eixo Bolivariano, onde a Revolução venezuelana encontre eco e aliados internacionais. A necessidade de ter uma frente unida e fortalecida justifica-se ao identificar um inimigo comum: o imperialismo norte-americano, como se verá a seguir.

Um novo desenho de alianças tem se estabelecido nos governos de Chávez. Temos como exemplo, no âmbito bilateral, as relações da Venezuela com Cuba, Estados Unidos e Colômbia. Na arena multilateral, são de especial destaque a saída da Venezuela da CAN e seu ingresso no MERCOSUL, além da criação da ALBA e de sua saída do FMI e do Banco Mundial. Por questões de espaço, serão desenvolvidos a continuação unicamente os casos de Cuba, Estados Unidos e a criação da ALBA.

O interesse da Venezuela em Cuba é o de desenvolver um vínculo entre dois projetos políticos similares; ajudar a diminuir os efeitos negativos do bloqueio econômico a Cuba por parte dos Estados Unidos; bem como aqueles do fim da proteção da URSS por meio da ampliação do fornecimento de petróleo venezuelano à ilha. A aproximação no campo comercial consolidou-se a partir da assinatura do Convenio Integral de Cooperación, em outubro de 2000, com a finalidade de promover o intercâmbio de bens e serviços em condições solidárias (ROMERO, 2008). A partir de 2004, a aliança entre ambos os países intensificar-se-á ainda mais, como será mostrado mais adiante, no plano da ALBA. Interessante notar que tal aproximação definitivamente supera o intercâmbio comercial e de serviços. Nas palavras de Chávez: “Ahora debemos mirar más allá, Cuba y Venezuela 
perfectamente pudiéramos conformar en un futuro próximo una Confederación de Repúblicas”6.

Mesmo que a política externa venezuelana já tivesse apresentado tendências que se afastavam da política externa tradicional, principalmente na diversificação de suas alianças temáticas e geográficas, foi só em 2004 que Chávez anunciou o início da etapa antiimperialista de sua Revolução. No discurso pronunciado no dia 16 de maio, uma semana depois do incidente dos paramilitares colombianos em território venezuelano, Chávez disse:

[N]unca como ahora desde aquí desde esta revolución nosotros habíamos señalado al imperialismo como lo estamos señalando, es decir, lo ratifico aquí, la revolución bolivariana después de cinco años y tres meses y un poco más de gobierno, y después haber pasado por varias etapas, ha entrado en la etapa antiimperialista. (MORENO, 2008, p137.)

Destarte, um novo oponente aparece explicitamente no mapa de política internacional venezuelano: o imperialismo norte-americano. Marco Aponte Moreno, ao trabalhar com as metáforas presentes nos discursos de Chávez entre 1999 e 2007, observa como existe uma evolução com referência aos Estados Unidos, uma vez que a noção de "guerra contra o imperialismo yanqui” aparece nos discursos como um elemento essencial a partir de 2004 (MORENO, 2008, p.135). Neste mesmo ano, é iniciada uma responsabilização pelos acontecimentos de abril de 2002 em Caracas; em 2005, aparece ainda a noção de capitalismo como mais um inimigo do país, apontando, mais uma vez, os Estados Unidos como os líderes desse sistema econômico. No conhecido discurso de Mar del Plata, na Cúpula dos Povos, Chávez referiu-se ao capitalismo como uma ameaça ao mundo e ao imperialismo como um agente opressor:

Los pueblos del mundo unido estamos en capacidad de unir a mil imperios [...] Así como fracasó el imperio americano en parar la Revolución Cubana, así fracasará en detener la Revolución Bolivariana [...] Si al imperialismo norteamericano, en su desespero, se le ocurriera invadir a Venezuela, se desarrollará en estas tierras la guerra de los cien años [...] El modelo capitalista neo-liberal que desde Washington arremete contra nuestros pueblos [...] Enterrar el capitalismo para parir el socialismo del siglo XXI. ¡Socialismo o barbarie! [...] El modelo capitalista que han

\footnotetext{
${ }^{6}$ Discurso de encerramento da VI Reunião da Comissão Mixta do Convênio Integral de Cooperação Binacional entre Venezuela y Cuba. (ROMERO, 2008).
} 
impuesto al mundo está acabando con el planeta tierra [...] La ambición capitalista ciega, borra no sólo la vista, los sentidos y la conciencia [...] Hay dos superpotencias mundiales en este momento: una amenaza con destruir al mundo, esa es la superpotencia estadounidense [...] La otra superpotencia está naciendo [...] Los pupilos de Bush en América Latina están cayendo uno a uno y la gente no acepta aquí Presidentes entreguistas y arrodillados al imperio. (PDT-RJ, 2005)

No âmbito individual, a lista de insultos contra o ex-presidente dos Estados Unidos é bastante extensa: "Eres un burro Mister Danger $^{7}$ [...] cobarde [...] asesino [...] inmoral [...] genocida [...] ¡Váyanse al Carajo yanquis de mierda! ¡Yanquis de mierda! ¡Váyanse al carajo cien veces!” (GLOBOVISIÓN, 2009).

Além das alianças e animosidades bilaterais, é possível encontrar um novo mapa político no contexto multilateral. A Política Externa desenvolvida pelo Presidente Chávez retoma a região da América Latina como estratégica e realiza uma seleção dos organismos internacionais, distinguindo aqueles que a Venezuela pode participar. A intenção da diplomacia venezuelana não é unicamente o aumento do intercâmbio comercial, mas sim a instituição de uma verdadeira convergência no processo de uma integração mais ampla. A promoção da Alternativa Bolivariana para a América Latina e o Caribe (ALBA) e da União de Nações Sul-Americanas (UNASUL), assim como o impulso de instituições e projetos de/para os latino-americanos (Petrolatina, o Banco do Sul, o gasoduto do sul, a União das Forças Armadas da América Latina, entre outros) representam os novos espaços de diálogo e aliança multilaterais e multitemáticos venezuelanos.

O projeto de integração certamente apresenta uma proposta inovadora para a noção de espacialidade, uma vez que Chávez desconstrói a noção tradicional de Estado soberano com fronteiras definidas e invioláveis. A proposta de integração do Presidente procura consolidar a Confederação de Nações idealizada por Bolívar. Mesmo se no cenário do MERCOSUL tal mensagem provavelmente não tenha tanto eco, a ALBA parece ser um espaço onde o discurso do Presidente é mais escutado. Ao se pronunciar em Mar del Plata contra a ALCA (Área de Livre Comércio das Américas), aliança proposta pelos Estados

\footnotetext{
7 Epíteto contra o Presidente George W. Bush, cujo nome vem do romance Doña Bárbara, escrito pelo romancista e ex-presidente venezuelano Rómulo Gallegos. Mr. Danger é um americano que se aproveita da falta de lei na região dos Llanos venezuelanos para roubar terras e fazer a sua vontade.
} 
Unidos no governo de George W. Bush, Chávez declarou: “ALCA, ALCA, Al carajo! Unidad, unidad, decía Bolívar: unidad esa debe ser nuestra divisa. Sólo unidos podremos derrocar al imperialismo y levantar a nuestros pueblos hacia una vida mejor” (PDT-RJ, 2005). Em contrapartida, Chávez propôs a criação da Alternativa Bolivariana, uma aliança internacional composta por Venezuela, Cuba, Equador, Nicarágua, Bolívia e alguns países do Caribe tendo como principal interesse "lutar conjuntamente contra os desafios do presente e do futuro" (ALBA site oficial, 2011).

O interessante é ver que na mesma medida em que alianças são construídas sob uma narrativa espacial específica, esta também legitima a negação da presença do país em organismos identificados pelo governo como espaços contaminados pelo "imperialismo". Exemplo disto é a saída do país do Banco Mundial, do Fundo Monetário Internacional e da Comunidade Andina (CAN), bem como a negação da participação na ALCA. A negação da presença, no entanto, implica o rompimento do diálogo e da participação multilateral, mostrando a dificuldade em participar de espaços de divergência. O Presidente Chávez cria, assim, um novo mapa político onde as alianças representam a estratégia para combater o imperialismo norte-americano e a constante ameaça à soberania do país, bem como a união necessária para conseguir o sonho de Bolívar, que vai além de uma integração puramente comercial.

\section{III) Espaços estratégicos: Negação e exclusão soberana do Outro}

No campo doméstico, onde Hugo Chávez apresenta uma clara concentração de poder e de autonomia para decidir nos quesitos do país, os espaços internos da Venezuela são também disputados entre chavistas e não chavistas, identificados como amigos ou inimigos do governo. A seguir será apresentado como Chávez defende soberanamente o espaço (político, institucional, mediático e econômico) daqueles que apoiam seu governo, em detrimento daqueles que divergem deste, cuja participação nesses espaços é negada.

A Organização não governamental Human Right Watch, publicou um informe em setembro de 2008, intitulado Una Década de Chávez: intolerancia política y oportunidades perdidas para el progreso de los derechos humanos en Venezuela. Nele afirma-se que a 
discriminação política tem sido uma característica definidora do governo de Chávez ao tolerar, incentivar e participar desses atos. Em algumas oportunidades o Presidente tem respaldado abertamente atos de discriminação e, em outras, tem incentivado os seus subordinados a tomar ditas medidas. A discriminação política no governo aumentou com a proposta da oposição de um Referendo Revogatório (RR) contra o Presidente Chávez em 2004. Para poder levá-lo a cabo recolheram-se, desde 2002, assinaturas visando obter os dois milhões apontados pela Constituição como necessários para conseguir tal direito. As pessoas que assinaram sofreram ameaçadas de represália e inclusão em listas que impediriam o acesso a empregos e serviços do governo. Em outubro de 2003, Chávez insinuou que a petição poderia ser utilizada no futuro contra os assinantes : "Los que firman contra Chávez, en verdad no están firmando contra Chávez. Estarán firmando contra la patria [...] Quedará registrado para la historia, porque va a tener que poner su nombre, su apellido, su firma, su número de cédula y su huella digital” (CIUDADANIA ACTIVA, 2006).

No Aló, Presidente de número 180, Chávez solicitou a cópia de todas as planilhas entregues pela oposição ao Conselho Nacional Eleitoral ${ }^{8}$ e determinou que estas fossem entregue ao deputado Luís Tascón, que seguidamente publicou a lista na Internet. A chamada "Lista Tascón”, composta por 2.340.000 nomes, foi utilizada para discriminar politicamente opositores do governo (HUMAN RIGHTS WATCH, 2008, p.17-19). Somente em abril de 2005, Chávez reconheceu o caráter discriminatório da Lista Tascón, após múltiplas denúncias de demissão ou recusa de contratação em órgãos públicos de pessoas que apareciam na lista.

A discriminação política foi respaldada e praticada abertamente na indústria petroleira. Depois da greve de dois meses da Petróleos de Venezuela S.A. (PDVSA) no início de 2002, o governo demitiu, até 2003, 18.000 empregados, em clara violação aos direitos laborais do país (HUMAN RIGHTS WATCH, 2008, p.203). A greve foi o ápice de uma luta pelo controle da PDVSA. Em fevereiro de 2002, Chávez demitiu o presidente da empresa e nomeou uma nova equipe ligada ao seu governo. Vários gerentes disseram que os novos diretores da empresa eram seleções políticas de pessoas

\footnotetext{
${ }^{8}$ Máximo órgão eleitoral da Venezuela.
} 
sem experiência e convocaram uma greve contra as repetidas intervenções do governo na gestão da empresa (HUMAN RIGHTS WATCH, 2008, p.203). Em resposta, Chávez anunciou emblematicamente ao vivo e em cadena nacional, no Aló Presidente de número 201, a demissão de sete altos executivos da empresaao som de apitos e ao ritmo de fortes “PA'FUERA!!! PA'FUERA!!!” OFFSIDE!!” do Presidente depois de dizer o nome de cada executivo:

\begin{abstract}
Anuncio la destitución, despido de las siguientes personas, han sido despedidos de sus cargos, ya está bueno, las siguientes personas: Eddy Ramírez, Director Gerente hasta el día de hoy de Palmaven. Pa'fuera [...] Esa Palmaven es de todos los venezolanos, así que señor Eddy Ramírez muchas gracias, está usted despedido, caballero. Luego está despedido, también muchas gracias por sus servicios, Señor Juan Fernández. Está despedido de Petróleos de Venezuela. [...] Vean ustedes el nivel de esta gente, se convirtieron en saboteadores de una empresa que es de todos los venezolanos (ALÓ PRESIDENTE, 2004c).
\end{abstract}

Em ambos os casos tem-se que frente a um cenário de polarização e a um discurso político que parece não oferecer espaço para a dissidência, as instituições públicas praticam, de fato, uma segregação entre bolivarianos, sob a justificativa de que seriam pessoas de confiança, e não bolivarianos que, por não serem adeptos ao processo revolucionário, não teriam a chance de participar de empresas que supostamente "Ahora son de todos".

O informe da Human Rights Watch afirma também que a administração do Presidente Chávez tem restringido o campo mediático por meio de diversas medidas que procuram alterar o controle e o conteúdo dos meios. Embora exista ainda no país um dinâmico debate público, observa-se uma clara mudança na simpatia ao governo por parte de meios privados, até então críticos. Hoje, a balança dos meios comunicativos inclina-se, de forma significativa, para o apoio ao Presidente, o que não é devido à criação de meios mais plurais, mas a uma atuação contra os meios de comunicação opositores e, ao mesmo tempo, à promoção de meios estatais oficialistas. A não renovação da concessão do contrato de Rádio Caracas Televisão (RCTV), em março de 2007, é o maior exemplo disto. Esse fato levou à exclusão da transmissão do canal de televisão mais antigo e visto pelos venezuelanos, por discordar abertamente do governo. Tentou justificar-se a decisão 
acusando RCTV de colaboradora dos acontecimentos de abril de 2002. Mas ao perceber que tal justificativa não tinha fundamento suficiente, Chávez apresentou sua medida como uma decisão soberana frente à necessidade de uma frequência aberta com cobertura nacional para o novo canal estatal Televisora Venezolana Social (TVES), que seria um canal socialista, qualitativamente melhor e mais justo. No último dia de transmissão de RCTV, Chávez declarou:

Decidí no renovar la concesión, me correspondió a mí [...] el comportamiento específicamente de esa televisora privada, la actitud, el atropello permanente contra la moral pública [...] esa televisora se convirtió en una amenaza para el país, para los niños, para las niñas [...] las telenovelas son como la (víbora) de cascabel. Eso es veneno puro, con una que otra excepción (ADNMUNDO.com, 2007).

O fim da concessão de RCTV é um claro exemplo de radicalização da não aceitação do Outro, na medida em que se escolhe eliminá-lo do cenário (mediático).

Também consta a insólita expulsão de dois representantes da divisão das Américas da organização não governamental independente ${ }^{9}$ Human Rights Watch (HRW), em setembro de 2008. O Diretor da divisão e o vice-diretor foram expulsos do país depois de um comunicado dos Ministros de Interior e Justiça e de Relações Exteriores, sob acusações de que “[o Diretor] irrespetó normas de la Constitución y la institucionalidad de la República Bolivariana de Venezuela” e, por isso, “en el pleno ejercicio de la soberanía y en nombre del pueblo venezolano, le notificamos a los referidos ciudadanos la obligación de abandonar de manera inmediata la Patria de Simón Bolívar” (BBC MUNDO.com, 2008). Este ato aconteceu após a publicação do relatório Una década de Chávez. Intolerancia política y oportunidades perdidas para el progreso de los derechos humanos, que descreve como o governo do Presidente Hugo Chávez tem enfraquecido as instituições democráticas e a garantia dos direitos humanos na Venezuela (HRW NEWS, 2008). Segundo o Diretor Executivo da HRW, “a expulsão da equipe é mais um exemplo da falta de tolerância do governo da Venezuela, reforçando com isto a mensagem, mesmo que os mensageiros tenham sido enviados a ir embora” (HRW NEWS, 2008).

\footnotetext{
${ }^{9}$ Segundo o site oficial da organização (http://www.hrw.org/), a Human Rights Watch é uma organização não governamental independente, ou seja, não aceita fundos governamentais, direta ou indiretamente.
} 
Nesse sentido, uma nova definição de espacialidade na arena doméstica, determinada a partir da noção de ameaça interna, é apresentada pelo Presidente Chávez. A tendência parece mostrar um entendimento do território venezuelano como “soberano” para decidir quem pode estar dentro e quem deve estar fora dele. No momento em que a presença do Outro é entendida como ameaça - o que não parece ser difícil uma vez que, para o governo, qualquer crítica ou divergência é traduzida nesses termos - passa a ser necessário impedir, excluir ou expulsar referida presença no território venezuelano. Uma lógica binária e excludente, que determina quem pode ou não ocupar certos espaços, está assim presente nos discursos e políticas do governo do Presidente Chávez.

\section{Conclusões}

Ao longo do presente trabalho observou-se que a construção da identidade e da política chavista está intimamente relacionada com o discurso do Presidente Chávez na medida em que se apresentam nele representações do chavismo (o Eu) e da oposição (o Outro). Essas representações, como defende Lene Hansen (2006), são feitas a partir de um movimento duplo de vinculação/afirmação e de diferenciação/negação. O diagrama apresentado por Hansen ilustrando esse processo, exemplificando a construção da identidade das mulheres no século XIX em justaposição à identidade do homem, pode igualmente ilustrar o processo de construção da identidade chavista em justaposição à identidade da oposição; bem como a defesa da identidade latino-americana justaposta ao que Chávez chama de imperialismo, como se observa a seguir: 

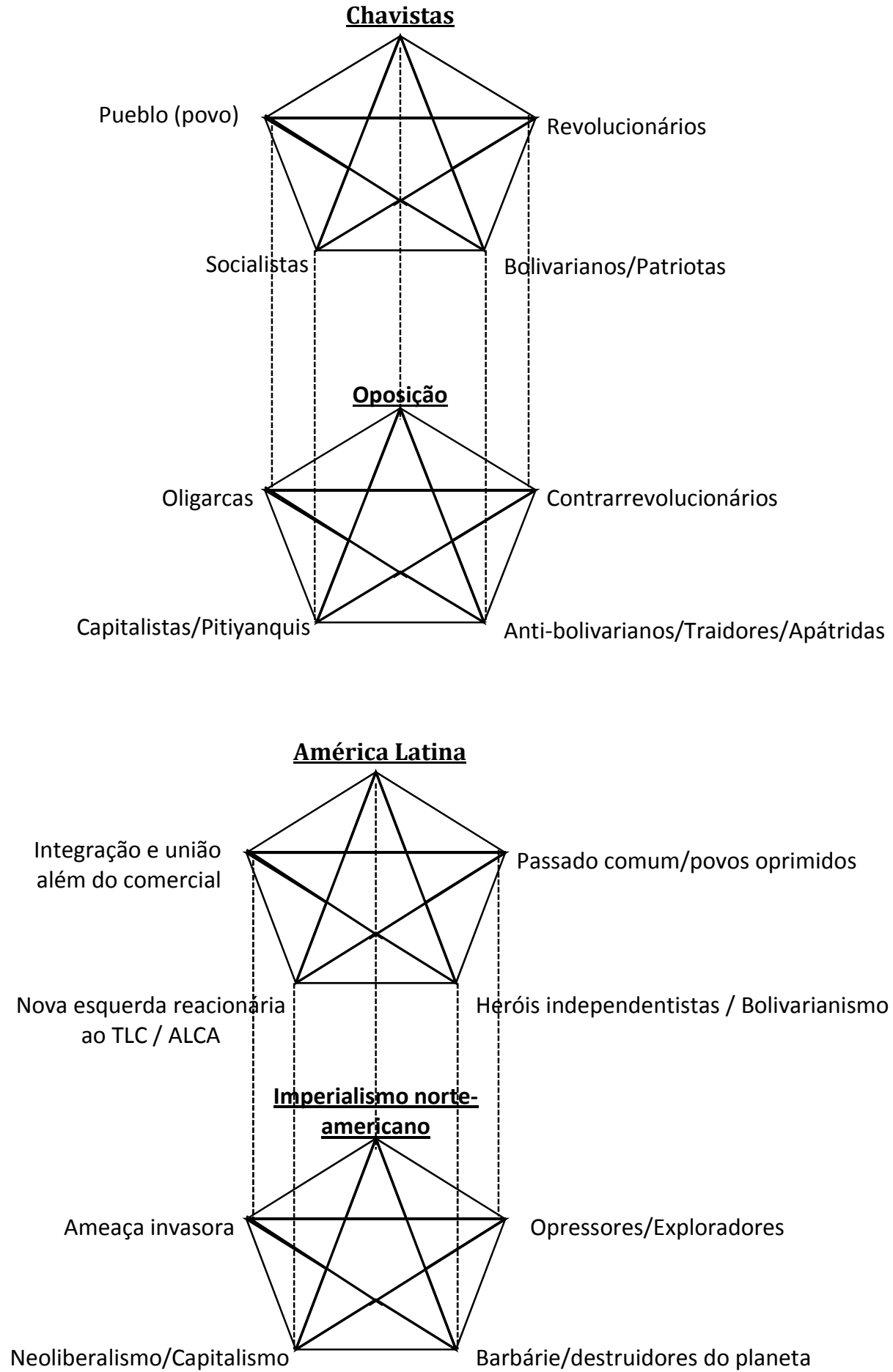
Observa-se, assim, que cada uma dessas identidades é construída a partir de um processo positivo de vinculação: no caso chavista, a representação destes como revolucionários, socialistas, do povo e bolivarianos vinculam dita identidade, sempre em contraste com as representações da oposição como oligárquica, pitiyanqui, contrarevolucionária ou anti-bolivariana. Um processo bastante parecido acontece com a identidade latino-americana construída pelo Presidente Chávez, onde esses povos são vinculados a partir das noções de um passado comum e heroico frente à opressão, o surgimento de uma nova esquerda reacionária às políticas neoliberais e que procura aprofundar as alianças além da esfera comercial. Essa identidade apresenta-se justaposta ao imperialismo norte-americano representado como uma ameaça à soberania dos países latino-americanos, em geral, e da Venezuela, especificamente, além de opressor, neoliberal e destruidor do planeta.

Chama-se a atenção que no caso particular do discurso do Presidente Chávez, as representações das identidades chavistas e da oposição dificilmente apresentam-se como conciliáveis. Na grande maioria das vezes, são representações binárias que estabelecem uma hierarquia entre os dois grupos e que parecem ser mutuamente excludentes (onde a presença de um impede a presença do outro). Muitas das representações utilizadas apresentam o prefixo de oposição (anti-bolivariano, contrarrevolucionário) ou de negação (apátrida), ou são representações antagônicas como: opressor/oprimido, capitalismo/socialismo, povo/oligarquia. Isso dificulta a aproximação entre os grupos. A linguagem de guerra, característica da grande maioria dos discursos de Chávez intensifica a polarização dessas representações na medida em que sugere constantemente uma ameaça iminente de invasão territorial ou de golpe de Estado por parte da oposição e/ou do imperialismo norte-americano. Essa linguagem reduz os oponentes do governo de Chávez a uma lógica em que eles representam uma ameaça para a existência chavista, passando assim a serem grupos irreconciliáveis e inassimiláveis.

A partir da narrativa espacial, vimos que o Presidente Chávez apresenta a reedificação de uma determinada ontologia baseada na representação do cenário internacional como um campo de batalha dividido entre amigos e inimigos, onde é 
necessária a definição do território de cada um dos grupos. A partir daí, a presença venezuelana é promovida dentro do campo traduzido como “amigo” (integração latinoamericana, MERCOSUL, ALBA) e o afastamento do campo “inimigo” (CAN, ALCA, FMI, Banco Mundial). Domesticamente, a tendência parece mostrar uma compreensão do território venezuelano como "soberano” para decidir quem pode estar dentro e quem deve estar fora do mesmo, tal como foi visto nos caso da expulsão dos representantes da Human Rights Watch. No momento em que a presença do outro é entendida como ameaça e fonte de desconfiança, passa a ser necessário impedir ou excluir dita presença nas empresas estatais, nos espaços públicos ou mediáticos, tal como foi o caso da expulsão de mais de 18.000 trabalhadores de PDVSA, ou o fim da concessão de RCTV.

A relevância do estudo da prática discursiva do presidente Chávez, vai além do reconhecimento de claras políticas excludentes, uma vez que, na visão de Walker, toda prática política, mesmo visando a inclusão, gera exclusão. No entanto, o que é importante de identificar é que o grande paradoxo do discurso de Chávez está em reivindicar voz para aqueles que nunca foram escutados, direitos para aqueles que nunca os usufruíram e visibilidade àqueles que nunca foram percebidos, sob o mesmo mecanismo de exclusão e de violência usado pelos impérios, Estados hegemônicos, e todos aqueles que o Presidente acusa hoje de opressores. Longe de se sublevar dessa dinâmica, o Presidente é fiel discípulo dela. São estes, talvez, os discursos mais delicados e problemáticos na medida em que se legitimam e proclamam como inclusivos, quando na verdade reedificam profundamente a exclusão.

É interessante retomar as palavras de Walker para entender a importância de perceber a reedificação específica de espaço-temporalidade apresentada pelo discurso de Hugo Chávez:

I offer a reading of modern theories of international relations as a discourse that systematically reifies an historically specific spatial ontology, a sharp delineation of here and there, a discourse that both expresses and constantly affirms the presence and absence of political life inside and outside the modern state and the only ground on which structural necessities can be understood and new realms of freedom and history can be revealed (WALKER, 1993, preface ix). 
Isso mostra certo otimismo por parte de Walker, na medida em que ao desvelar e desnaturalizar as construções narrativas espaço-temporais reedificadas pela modernidade, o autor sugere que novos entendimentos da história e novas esferas de liberdade poderiam ser atingidas. Assim sendo, nos contagiamos desse otimismo e afirmamos que identificar as reedificações específicas de espacialidade nos discursos do Presidente Chávez é um primeiro passo para que outras formas de construção de identidades e políticas (não binárias nem excludente) possam ser (re)pensadas na Venezuela. 


\title{
Referências
}

\author{
ADNMUNDO.com. Manifestaciones a favor de RCTV en su último dia de emisión \\ [s.l], 27 maio 2007. Disponível em \\ $<$ http://www.adnmundo.com/contenidos/politica/venezuela-hugo-chavez-rctv-cierre- \\ ultimo-dia-emision-27-05-07-pi.html> Acesso em: 09 jun.2011.
}

ALBA, site oficial. ¿Qué es el ALBA?. Disponível em

$<$ http://www.alianzabolivariana.org/modules.php?name=Content\&pa=showpage\&pid=208 $\underline{0}$ >. Acesso em 10 jun. 2011.

ALÓ PRESIDENTE. Aló Presidente 1. 23 maio 1999. Disponível em:

<http://alopresidente.gob.ve/materia_alo/25/1530/?desc=alo_presidente_1.pdf $>$ Acesso em 17 set. 2010.

ALÓ PRESIDENTE. Aló Presidente 180. 1 fev 2004a. Disponível em:

$<$ http://alopresidente.gob.ve/materia_alo/25/p--20/tp--32/> Acesso em 27 set. 2010.

ALÓ PRESIDENTE. Aló Presidente 200. 1 ago. 2004b. Disponível em:

$<$ http://alopresidente.gob.ve/materia_alo/25/p--18/tp--32/> Acesso em 30 set. 2010.

ALÓ PRESIDENTE. Aló Presidente 201. 22 ago. 2004c. Disponível em:

$<$ http://alopresidente.gob.ve/materia_alo/25/p--18/tp--32/> Acesso em 30 set. 2010.

ALÓ PRESIDENTE. Aló Presidente 202. 29 ago. 2004d. Disponível em:

$<$ http://alopresidente.gob.ve/materia_alo/25/p--18/tp--32/> Acesso em 30 set. 2010.

ALÓ PRESIDENTE. Aló Presidente 214. 27 fev 2005. Disponível em:

$<$ http://alopresidente.gob.ve/materia_alo/25/p--17/tp--32/> Acesso em 30 set. 2010.

ALÓ PRESIDENTE. Aló Presidente 250. 20 mar 2006. Disponível em:

$<$ http://alopresidente.gob.ve/materia_alo/25/p--13/tp--32/> Acesso em 15 abr. 2011. 
ALÓ PRESIDENTE. Aló Presidente 295. 23 set, 2007. Disponível em:

<http://alopresidente.gob.ve/materia_alo/25/p--9/tp--32/> Acesso em 01 abr. 2011.

\section{BBC MUNDO.com. Comunicado oficial República Bolivariana de Venezuela} Ministerio del Poder Popular para Relaciones Exteriores. 18 set. 2008. Disponível em $<$ http://news.bbc.co.uk/hi/spanish/latin_america/newsid_7626000/7626086.stm> Acesso em 15 maio 2011.

BLANK, Carlos Aponte; CALCAÑO, Luis Gómez. El régimen político en la Venezuela actual. Instituto Latino Americano de Investigaciones Sociales. Caracas, fev. 2009. Disponível em $<$ http://www.convite.org.ve/Publicaciones/RegimenpoliticodeCarlosAponte.pdf $>$. Acesso em 20 jul 2010. Tradução livre.

BUTLER, Judith. Excitable Speech. Nova York \& London: Routledge, 1997. 185p.

CHÁVEZ, Hugo. Discurso del 19 de abril de 2010. Disponível em: $<$ http://www.google.com.br/url?sa=t\&rct=j\&q=\&esrc=s\&source=web\&cd=2\&ved=0CCkQ FjAB\&url=http\%3A\%2F\%2Fxa.yimg.com\%2Fkq\%2Fgroups\%2F7177584\%2F59775306 \%2Fname\%2FHUGO\%2BCHAVEZ\%2B\%2BLA\%2BNOCHE\%2BANTES\%2BDEL\%2 B19\%2BDE\%2BABRIL.18.04.2010.doc\&ei=bNJDULmRPKjm0QGq94HoCg\&usg=AFQj CNEFeXIKpSZeo4A4snLwK9xY-e_ZOg> Acesso em 01 abr. 2011.

CIDADANIA ACTIVA. La Lista: Un Pueblo Bajo Sospecha. Caracas, 2006. (43:29) $<$ http://video.google.com/videoplay?docid=-8187459075291793700>. Acesso em 14 jun. 2008.

COLMENARES, Martha. Lista de los insultos de Chávez. 30 out. 2008. Disponível em http://www.marthacolmenares.com/2008/10/30/lista-de-los-insultos-de-chavezclasificados-por-categorias-incluye-videos/>). < Acesso em 04 nov. 2010. Tradução livre.

GLOBOVISIÓN. Los insultos de Chávez. (4:41). 19 mar. 2009. Disponível em $<$ http://www.youtube.com/watch?v=yFohnJ8N5Us\&feature=related> Acesso em: 25 maio 2011. 
HANSEN, Lene. Security as practice: discourse analysis and the bosnian war. Nova York: Routledghe, 2006. 259p.

HRW News. Venezuela: Human Rights Watch Delegation Expelled. São Paulo, 19 set 2008.

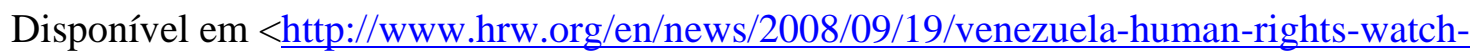
delegation-expelled $>$. Acesso em: 17 jun. 2011.

HUMAN RIGHTS WATCH. Una década de Chávez: intolerancia política y oportunidades perdidas para el progreso de los derechos humanos. Caracas, set. 2008. 275p.

KRAUZE, Enrique. El poder y el Delirio. Barcelona: Tusquets. 2008. 373p.

MORENO, Marco Aponte. Metaphors in Hugo Chávez’s political discourse: conceptualizing nation, revolution, and opposition. Nova York. 2008. (Doutorado em Filosofia) - Faculdade de Literatura e Linguagens Hispánica e Luso-Brasileira. Disponível em <http://eprints.aston.ac.uk/7389/1/APONTE MORENO FINAL THESIS.pdf $>$. Acesso em 21 mar. 2011.

ORGANIZAÇÃO DE ESTADOS AMERICANOS. Situação na Venezuela, 13 abr. 2002. Disponível em $<$ http://www.oas.org/xxxiiga/portugues/documentos/resolucion_venezuela.htm>. Acesso em 26 jun. 2011.

Apóio à democracia na Venezuela. 18 abr. 2002. Disponível em <http://www.oas.org/XXXIIGA/portugues/documentos/resolucionag_venezuela.htm.>. Acesso em 26 jun. 2011.

PASQUALI, Antonio. El discurso chavista: una autodefinición. 16 jan. 2006. Disponível em < http://www.analitica.com/va/politica/opinion/4575153.asp> . Acesso em 02 set. 2010.

PDT - RJ. Documento: discurso de Chávez em Mar del Plata. Disponível em <http://www.pdt-rj.org.br/primeirapagina.asp?id=765>. Acesso em03 set. 2010.

PSUV: Blog de opinión y noticias relacionadas al Partido Socialista Unido de Venezuela. Cronología de los años de gobierno de Hugo Chávez. Disponível em 


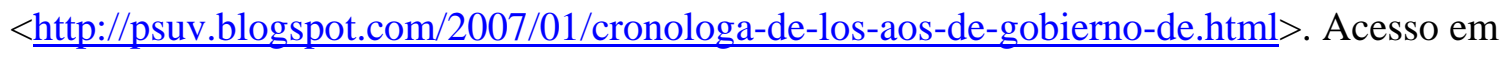
17 out. 2010.

ROMERO, Juan Eduardo. Discurso político, comunicación política e historia en Hugo Chávez. Ámbitos, vol. 1, n. 13-14, 2005.

ROMERO, Carlos A. La entrada de Venezuela en el Mercosur: repercusiones internas. ILDIS, Caracas, set. 2007. Disponível em http://www.ildis.org.ve/website/administrador/uploads/PresentacionMERCOSURRomero.p df Acesso em fev. 2008.

Venezuela y Cuba: una seguridad diferente. ILDIS, Caracas, dez. 2008.

Disponível em $<$ http://www.ildis.org.ve/website/administrador/uploads/DocumentoFinalCarlosRomero.pd f>. Acesso em 20 maio 2008.

WALKER, R.B.J. Inside / Outside: international relations as political theory. Cambridge: Cambridge University Press. 1993. 202 p.

. The Double Outside of the Modern International. Ephera: Global Conflics. vol. 6, n.1, 2006. 